\section{Use of Qat in the UK}

\section{Dear Sirs}

A recent newspaper article (The Independent, 1992) suggested that the plight of some Somalian refugees in this country is compounded by the adverse effects of heavy use of Qat, a mood-altering plant. Last year I encountered an acute psychotic episode associated with the use of Qat.

My patient, a 28-year old Somalian male student, was brought to me by friends concerned by his agitated, restless, sleepless state. He described paranoid ideas and had felt suicidal. There was no previous psychiatric history. He was admitted informally to a local psychiatric unit where his symptoms settled rapidly, was discharged after a few days on no medication, and has remained well since.

It emerged that his symptoms had followed a spell of heavy Qat consumption.

Qat (Gat, Khat, or Mira) is the leaves and young shoots of Catha Edulis, a tree that grows at high altitude in East Africa (Ghodse, 1989; Kennedy, 1987). Originating in the Yemen, it is traditionally used in the Middle East and parts of North and East Africa by chewing or, formerly, by infusing the leaves (Arabian or Ethiopian tea). It has been described as a remedy for depression since the 13th century and is often a pleasurable group activity after a traditional meal, in rooms specially set aside and furnished, and is an important and traditional part of local social life. Official business and commerce are often conducted while Qat is chewed during the afternoon siesta. It is also used by students and local lorry drivers to combat fatigue. Active ingredients include Cathine (D-pseudonorepinephrine) and Cathinone; effects are described as mildly stimulant and euphoric but may lead to restlessness, sleeplessness, anorexia, gastro-intestinal symptoms and (rarely) a psychotic reaction. Psychological but not physical dependence is said to occur (an abstinence syndrome has not been described) and heavy users and their families may experience economic hardship in their home countries (Baasher, 1983). Several countries have attempted to ban or regulate its use; this has been debated since the 16th century (Kennedy, 1987) in the Yemen, where it is an important cash crop. Its use is not illegal in the UK and it is imported, freshly gathered, by air.

In its original setting, Qat has been used for centuries as a mild and usually harmless stimulant and social lubricant of cultural and economic importance, sanctioned by tradition. When transmitted into another culture, will there be different health implications?

Montpelier Health Centre

Stefan Cembrowicz

Bath Buildings, Montpelier

Bristol BS6 5PT
References

BAasher, T. (1983) What is Khat? In Drug Use \& Misuse (eds. G. Edwards. A. Arif and J. Jaffe) pp. 42-49.

GHODSE, H. (1989) In Drugs \& Addictive Behaviour. London: Blackwell, pp. 87-88.

KENNEDY, J. G. (1987) The Flower of Paradise. (Dordrecht: D. Reidel)

The Independent, 27.3.92, p. 6.

\section{Cannabis psychosis}

\section{DeAR SIRS}

Dr Huw Thomas (Psychiatric Bulletin, September 1992, 16 572) has perfectly illustrated the problem with the current thinking on cannabis and psychosis I wrote about in my letter (Psychiatric Bulletin, May 1992. 16, 310-311). I have to agree with him that there are several different interactions between the drug and psychotic illness, and that this leads to confusion. The confusion arises because there is no specific symptom cluster associated with cannabis use, and the psychiatric presentations can mimic other psychotic states. Professor Cohen makes this point quite clearly in saying that alcohol and cannabis use, if investigated in patients attending depot clinics, could remove the schizophrenic label from many of them (Cohen, S.I., Psychiatric Bulletin, September 1992, 16, 513).

I argued previously that it is time to use an aetiological, and not symptom-based, system of diagnosis in the case of cannabis psychosis. This would remove much of the confusion and even denial of the existence of the entity. How can it continue to be argued, when psychotic symptoms follows heavy use of the drug in a subject with no other aetiological factors present, that it is not a cannabis psychosis? The diagnosis can always be revised if other, previously unknown, factors come to light. Are other diagnoses not revised at times?

JAMES EvA

Cell Barnes Hospital

St Albans AL4 ORG

Correspondence on this topic is now closed-eds.

\section{Psychogeriatric care}

\section{Dear Sirs}

Benbow \& Jolley's survey (Psychiatric Bulletin, September 1992, 16, 533-535) confirms the shift of provision of long-stay residential care out of old mental hospital wards and into nursing homes in the private and voluntary sector. The authors are unenthusiastic about this shift, are concerned about the loss of consultant 'sovereignty' over beds and the inevitable changing face of consultant work.

Since 1984 we have pursued vigorously a policy of joint development of specialist nursing homes for 